\title{
Trauma e historia. Reflexiones desde la trastienda
}

\section{Trauma and history. Reflections from the back room}

\author{
Florencia Levín \\ florencia.levin@gmail.com \\ Universidad Nacional de General Sarmiento - \\ CONICET, Argentina
}

Cita sugerida: Levín, F. (2021). Trauma e historia. Reflexiones desde la trastienda. Sociohistórica, 47, e130. https://doi.org/10.24215/18521606e130

\begin{abstract}
Resumen: Este artículo, que reflexiona sobre la trastienda de la labor de investigación, parte de la consideración de que la metodología de análisis no constituye una dimensión aislada y meramente técnica del trabajo del historiador sino que es el aspecto encargado de articular orgánicamente la empiria con los fundamentos ontológicos de la historia. Así, lo metodológico no se reduce al conjunto de procedimientos estandarizados y previstos para una investigación, sino que comprende un trabajo que refiere antes que nada a la construcción de categorías operativas que intervienen incluso en lo que se denomina definición de objeto. En las páginas que siguen, intento explorar los alcances de estos postulados en el caso del abordaje de la historia reciente y de los llamados pasados traumáticos.
\end{abstract}

Palabras clave: Trauma, Historia reciente, Experiencia, Semántica histórica, Epistemología de la historia.

\begin{abstract}
In this work, in which I reflect on the back room of the research work in history, starts from the consideration that methodology doesn't constitute an isolated and merely technical dimension of the historian's work, but rather is the aspect in charge of organically articulating the empirical work with the ontological foundations of history. Thus, the methodological is not reduced to the set of standardized and anticipated procedures for an investigation, but includes a work that refers first of all to the construction of operational categories that intervene even in what is called the definition of an object. In the pages that follow, I try to explore the scope of these postulates in the case of the approach of recent history and the so-called traumatic pasts.
\end{abstract}

Keywords: Trauma, Recent history, Experience, Historical semantics, Epistemology of history.

Acostumbramos a decir que "llevamos" una conversación, pero la verdad es que, cuanto más auténtica es la conversación, menos posibilidades tienen los interlocutores de "llevarla" en la dirección que desearían

Hans-Georg Gadamer, Verdad y método, 1917, V. I, p. 461

Antes de comenzar con el desarrollo de los temas que nos convocan, me gustaría resaltar la enorme pertinencia y relevancia que reviste la inquietud por la dimensión metodológica de la investigación histórica, ya que ésta habitualmente ocupa un lugar secundario y al margen de las principales inquietudes y debates historiográficos. Esta falta generalizada de interés crítico es verdaderamente llamativa pues la metodología 
constituye el aspecto más frágil de la arquitectura historiográfica en tanto es capaz de revelar la artificialidad de sus resultados y, en palabras de Michael de Certeau, las condiciones de su propio idiotismo. ${ }^{1}$ En el caso de la historia reciente argentina, dentro del cual se inscriben mis aportes, considero que tal dimensión es particularmente relevante ya que el campo académico se ha expandido muy velozmente sin la mediación de un desarrollo epistemológico acorde con los desafíos implicados en sus propios objetivos fundacionales; esto es, lidiar con pasados abiertos, "que no terminan de pasar" y que son objeto de fuertes disputas interpretativas, trasversales al ámbito de lo público y de lo privado. Por ello, valoro especialmente esta iniciativa y agradezco mucho a las organizadoras por haberme invitado a participar.

Como espero dejar debidamente argumentado en el transcurso de este ensayo, no concibo la metodología como una dimensión aislada y meramente técnica del trabajo de historiar, sino como el aspecto encargado de articular orgánicamente la empiria con los fundamentos ontológicos de la historia. Así, lo metodológico no se reduce al conjunto de procedimientos estandarizados y previstos (anticipadamente) para una investigación, sino que comprende un trabajo que refiere antes que nada a la construcción de categorías operativas que intervienen incluso en lo que se denomina construcción de objeto. De modo que la pregunta por la metodología de investigación en historia presupone la necesidad de explicitar(se) los presupuestos teóricos que sostienen una investigación, así como la necesidad de reflexionar sobre los vínculos internos que se establecen entre todos los elementos intervinientes en el proceso. Todo esto nos advierte, en el fondo, sobre la artificialidad de la separación entre la historia, la teoría de la historia, la epistemología de la historia y la filosofía de la historia, relegadas estas últimas, de modo exclusivo, al ámbito de injerencia de la filosofía, lo que revela el lugar de vacancia que sostiene la construcción y la reflexión metodológica sobre la escritura de la historia en la gran mayoría de los casos. Porque la inquietud por la trastienda de la investigación histórica esconde la punta del ovillo que desenvuelve, primero, el problema de los vínculos entre historia y ciencia, y tras él, la pregunta más fundamental por lo específico de la condición humana. Desde luego, semejante problemática convoca una empresa intelectual que me excede ampliamente y que incluso forma parte de mis propias condiciones de posibilidad de pensamiento intelectual. Intentaré, no obstante, reflexionar sobre mi práctica de investigación en el marco de esta perspectiva. Como se verá por el contenido y la extensión del desarrollo, condensaré en la primera parte el núcleo de mi argumentación, imprescindible para abordar el resto de los ítems de reflexión propuestos.

\section{INSPIRACIÓN METODOLÓGICA}

Para hablar de metodología, lo primero que tengo que explicitar es mi punto de anclaje, el cual se filia en la tradición hermenéutica y, dentro de sus vericuetos y ramificaciones, se identifica con los aportes de la hermenéutica filosófica filiada en el nombre de H. G. Gadamer ${ }^{2}$ y entiende por tanto a la historia como una disciplina abocada a un trabajo de comprensión y transformación. Parto de la consideración de que las palabras, materia prima por excelencia, aunque por cierto no la única, con la que trabajamos los historiadores, tienen vida propia. Una vida que escapa a cualquier encasillamiento de diccionario e incluso al control de los hablantes. ${ }^{3}$ Es decir que, si bien ellas son capaces de dar cuenta de la experiencia humana, otorgando cuerpo y forma a los sentidos y significados de la historia (después de todo, no otra cosa es la experiencia sino una meta-experiencia tamizada por la palabra), sólo pueden hacerlo de modo fallido ya que entre las palabras y el mundo interior de las personas existe una cesura infranqueable incluso para el propio sujeto de la experiencia, ya sea que se trate ésta de la experiencia de vivir la historia, ya sea que se trate de la experiencia de escribirla. Por ello, las palabras constituyen al mismo tiempo una representación fallida de la experiencia humana y una huella de su aquí y ahora, único e irrepetible. Al ser capaces de encarnar lo propiamente propio de su origen, son también capaces de performar lo propiamente propio del presente, que emerge como efecto a partir de esa diferencia y se integra a las condiciones de posibilidad ( $\mathrm{y}$ a las condiciones de producción) del 
sentido histórico de la historia. ${ }^{4}$ De modo que en la escritura del pasado están involucradas al mismo tiempo la historicidad de la experiencia pasada y la de la experiencia presente de su (re)escritura, y por ello involucra al mismo tiempo un trabajo de comprensión y de transformación. ${ }^{5}$ El concepto gadameriano de fusión de horizontes da cuenta de este aspecto único y específico del trabajo de historiar. ${ }^{6}$

Por todo lo anterior es evidente que la Begriffsgeschichte o historia conceptual, disciplina hermenéutica que aborda empíricamente la historicidad de los conceptos de la historia y se interroga por los vínculos que sus transformaciones semánticas guardan con los procesos de cambio social, constituye un punto de referencia insoslayable y una fuente fundamental de aprendizaje teórico-metodológico. Sin embargo, al menos con respecto a la perspectiva canonizada de dicha escuela, encuentro algunas diferencias importantes. ${ }^{7}$ La más evidente consiste en que mientras ellase ocupa de los conceptos denominados "conceptos", ${ }^{8}$ y más específicamente de los llamados "conceptos fundamentales de la historia", a mí me interesan los procesos sociales de semantización de la experiencia histórica de la historia (particularmente del terrorismo de Estado y la desaparición de personas como fenómeno social), por lo que la diferencia no reside únicamente en el recorte de objeto y en los criterios de construcción del corpus implicados, sino también, más ampliamente, en todo el planteo teórico metodológico: mientras que la Begriffsgeschichte pondera la dimensión normativa de los conceptos subyacentes en la erudición, a mí me interesan en cambio por su relación con la dimensión de la experiencia histórica. ${ }^{9}$ Por otro lado, hay distintas teorías de la lengua implicadas. Muy sintéticamente, podría decir que Koselleck parte de una diferencia inmanente entre la realidad lingüística y la realidad extralingüística (ver 2004, p. 30); en cambio, en mi trabajo considero "la realidad" como un constructo al mismo tiempo lingüístico y extralingüístico. Similarmente, lo mismo podría decirse del denominado verbum interius (Lythgoe, 2009, p. 289)..$^{10}$

Es así que estas diferencias y desplazamientos, junto con $\mathrm{mi}$ interés específico por el carácter traumático ${ }^{11}$ de la historia reciente, me han llevado a requerir de aportes de otras disciplinas del conocimiento (particularmente de la filosofía, como es evidente, pero también del psicoanálisis, la psicología genética, la semiología y la lingüística), sin los cuales no hubiera logrado arribar a la construcción de mi artificio de conocimiento. ${ }^{12}$ En orden de ponderar los aportes metodológicos que estas disciplinas me han brindado, es preciso detenerse por un momento en algunos detalles específicos de la trastienda de la investigación histórica.

Dado que, acorde con lo antedicho, no se puede presuponer que mi objeto de estudio tenga una existencia anterior a la investigación o, mejor dicho, que tenga algún tipo de existencia empírica a secas (su única existencia empírica posible es la de la realización de la obra de historia que lo aborda), ${ }^{13}$ no puedo sino romper con la naturalización de su supuesta preexistencia que está habitualmente implicada en los abordajes tradicionales de corte empirista. Esta dificultad específica, sin embargo, no debería ser ajena a la de ningún abordaje de la historia ya que ésta se construye entre el afuera y el adentro del artefacto historiográfico, y en ese sentido ningún objeto de la historia es verdaderamente empírico. Vale decir, ningún objeto de la historia está materialmente incrustado en ella. El denominado "trabajo de construcción de objeto" en el marco de la investigación comprende precisamente el trabajo de acoplamiento entre elementos que provienen de órdenes de realidad diversos, empíricos y no empíricos, por lo que no es tan sencillo construir un sistema de mediaciones que los nivele. Vale decir que las llamadas fuentes primarias, constituidas como tales por medio de un trabajo de archivo que establece el dominio de su objetualización (de Certeau, 1985), son autónomas del objeto de estudio que, por su parte, es un constructo abstracto producto de un trabajo teóricometodológico, ${ }^{14}$ y que éste no coincide con el objeto empírico, cualquiera sea su entidad metafísica (es decir, indistintamente que se trate de una persona, de un grupo de personas o de algún tipo de entidad producida por la actividad humana), ${ }^{15}$ que constituye el verdadero referente y objeto de la historia. Hemos comenzado sugiriendo que ni siquiera es posible adjudicar al sujeto una plena correspondencia consigo mismo...

De modo que estos elementos, habitualmente concebidos como preexistentes a una investigación, son en verdad el resultado y al mismo tiempo su condición de posibilidad. Poner en relación todos estos elementos, 
algunos de los cuales están adentro y otros afuera del discurso histórico ${ }^{16}$, supone un constante trabajo de ajuste metodológico cuyo objetivo último es lograr una coherencia entre empiria y teoría y, más ampliamente, entre la historia escrita y la historia vivida. Ello es posible gracias a la introducción de representantes semánticos del objeto empírico en el plano discursivo de la obra histórica, entre los que se destaca el "objeto empírico" como formulación meta-discursiva. ${ }^{17}$

La movilidad en los "cimientos" del constructo historiográfico que acabo de exponer, habitualmente ocluida por la fetichización de la objetividad científica por parte del sentido común historiográfico (ver Naishtat, 2009), se aprecia, en el caso de mi trabajo doctoral, en la irresoluble tensión entre el objeto de estudio (los sentidos históricos del pasado traumático) y el lugar inevitablemente protagónico (y estructuralmente necesario) de Clarin y los humoristas del diario en mi trabajo. Por tanto, aun cuando en términos teórico-metodológicos yo esté en condiciones de establecer con claridad la diferencia entre estos elementos, no podría, en cambio, señalarla específicamente en ningún párrafo de la obra escrita, en donde se subsumen y superponen los unos con los otros. Se trata de un aspecto propio del nivel meta-reflexivo.

Yendo entonces a las fuentes de inspiración, puedo mencionar en primer lugar la relevancia de los aportes provenientes de la semiología, ya que me brindaron no sólo conocimientos técnicos imprescindibles para el abordaje de discursos mediáticos y específicamente del humor gráfico que analicé como objeto empírico en mi trabajo doctoral, sino porque, de un modo más profundo, me permiten también comprender la historia como dispositivo de mediación, lo cual sin duda ha impactado en mi comprensión de la historia en sí misma. Vale decir que, más allá de lo que efectivamente puedan decir las viñetas sobre la historia vivida y en particular sobre la historia reciente argentina, el lenguaje humorístico reviste un carácter ejemplar ya que trabaja mediante la desnaturalización de los factores que intervienen en el proceso de mediatización y que los discursos "serios" dan por sentado, exhibiendo en el nivel meta-discursivo la artificialidad de la mediación semántica en cuanto tal (Masotta, 1976). ${ }^{18}$ Es por ello que reviste un valor ejemplar. Particularmente, el famoso "globo de diálogo" o baloom ${ }^{19}$ habilita un desdoblamiento extra de los planos de la realidad que tiene muchas consecuencias interesantes, ya que evocan una escena otra plasmando mediante el dibujo lo que en el registro de la palabra tiene únicamente una dimensión imaginaria. Así, un mismo elemento designa indistintamente el diálogo interno y el diálogo interpersonal. Por ello, el modo de estar ahí de lo interno ocurre a partir de su literalización gráfica y, por tanto, de la des-desnaturalización que ocasiona su mostración. ${ }^{20}$

En ese mismo orden, puedo mencionar la relevancia de las llamadas entidades imaginarias propias del análisis del discurso ya que contribuyen a problematizar y deconstruir metodológicamente las nociones de sujeto histórico y realidad histórica. Ciertamente, categorías como las de prodestinatario, contradestinatario y paradestinatario, que construye Eliseo Verón (1996) para dar cuenta de lo que llama discursos adversativos, permiten no sólo concebir la diferencia entre los sujetos empíricos de la historia y "el sujeto de la Historia", sino que, más importante todavía, permiten desentrañar los vínculos co-constitutivos entre ambos; es decir, la medida en que la experiencia de la historia está sostenida y producida también en el orden de lo imaginario por una descomposición del sujeto conforme a la mulitiplicidad de entidades que intervienen dinámicamente en la constitución de cada sujeto en cuanto tal. ${ }^{21}$ Así, mientras la noción de emisor remite cada vez a un aquí y a un ahora en el que un sujeto empírico se constituye como sujeto del habla, las entidades imaginarias pueden referir o no a entidades empíricamente específicas o especificables.

Ahora bien, es claro que para la definición ontológica de mi objeto de estudio, más ampliamente para mi concepto de historia operante, resulta insoslayable la marca que ha dejado mi breve experiencia como estudiante en la Facultad de Psicología de la UBA, ${ }^{22}$ ya que ella me brindó la oportunidad de adquirir conocimientos verdaderamente relevantes para mi trabajo, relativos a las consecuencias cognitivas del desarrollo genético y el funcionamiento de la psiquis. Estos conocimientos, cuyos efectos fueron sedimentando lenta y trabajosamente a lo largo del tiempo, propiciaron la construcción de una mirada antropológica sobre el campo disciplinar, que está en la base de mi conceptualización operativa de la historia 
reciente como un aspecto específico de su propio objeto de estudio (2013a) y del giro reflexivo que ésta propició a posteriori. Particularmente, los desarrollos teórico-metodológicos que he realizado sobre el trauma histórico hubieran sido impensables sin la lectura de Freud, Piaget o Lacan.

Finalmente, volviendo la mirada sobre mi producción, espero que se entienda en qué sentido considero que cada una de mis investigaciones empíricas constituye tanto un resultado como la condición de posibilidad de la reflexión epistemológica, la cual es, por su parte, la condición de posibilidad de su desarrollo teórico... Por eso siempre hay un gap o desfasaje, ya que la mayor fuente de inspiración teórica es el aprendizaje dejado por la experiencia empírica, por lo que suele “actualizarse” siempre un pasito más atrás. ${ }^{23}$

\section{ACERCA DE LOS CONCEPTOS}

Retomando lo anteriormente desarrollado, existen varios conceptos que intervienen en el proceso de definición de objeto en mi trabajo. Algunos de ellos refieren al objeto de estudio en un sentido muy abstracto, como podría ser el concepto de sentido; otros, en términos teóricos, como el concepto de trauma ${ }^{24}$ que define el fundamento ontológico del pasado que abordo, y otros en términos operativos, con implicancias metodológicas, como los conceptos de hiato y resto, que me permiten articular en el nivel de la empiria el problema del sinsentido y la rotura en la cadena de significación. ${ }^{25}$ Vemos que todos estos conceptos, sentido-trauma-hiato-resto, refieren desde distintas dimensiones al objeto de estudio y por lo tanto permiten construir relaciones significativas entre los materiales diversos y heterogéneos que constituyen la materia prima de una investigación. Ahora bien, no siempre es posible trazar con tanta claridad las cadenas de correspondencia entre los conceptos ni tan siquiera delimitarlos con entre sí. Esto ocurre particularmente con conceptos tales como violencia, que para el caso de la historia reciente argentina constituye, a mi entender, el concepto vector que define todo el proceso de semantización del ciclo histórico cuyo inicio se asocia con el Cordobazo ${ }^{26}$ y que requiere de esfuerzos de "desambiguación" sesudos y creativos. ${ }^{27}$

Por todo esto, considero importante ponderar, para ordenar esta respuesta, el rol que revisten las nociones operativas de categoría nativa y categoría erudita, que sustentan la clasificación científica de las fuentes conforme a su diferenciación como "fuentes primarias" y "fuentes secundarias" para la historia. La relevancia de este par categorial, como no podría ser de otra manera, deriva sin embargo no de esta diferencia, propia de la historiografía cientificista, sino del hecho de que se considera que tal diferencia no proviene de ningún determinismo ni de ninguna inmanencia, sino simplemente de decisiones metodológicas en el marco de una consideración dinámica y sistémica de los distintos elementos que componen el material de una investigación, entre otras cuestiones porque, si bien no hay dudas del carácter nativo de los discursos primarios, es imposible sostener, en cambio, en el caso de las llamadas categorías eruditas como también en los discursos eruditos, la perspectiva universal que cada una de ellas pretende para sí misma, particularmente para el caso de la historia reciente argentina, en la que confluyen en la persona del historiador tanto el sujeto del conocimiento como el sujeto de la experiencia de la historia objeto del conocimiento histórico. ${ }^{28}$

\section{CRiterios PARA LA SELECCión Y ORGANIZACión DEL CORPUS}

De lo anterior se desprende la dimensión metateórica de mis criterios de abordaje y organización de los textos, ya que se trata de encontrar modos de organización que me permitan superar la rigidez y el encorsetamiento de los criterios de clasificación de las fuentes conforme a los conceptos de natividad y erudición propios del modelo nomológico deductivo de la historiografía cientificista. ${ }^{29}$ Es que el ordenamiento de las fuentes en términos de primarias y secundarias, como compartimentos estancos, fijos e inamovibles no es productivo en el caso de la historia reciente, ya que las fuentes "secundarias" podrían ser leídas al mismo tiempo como nativas y eruditas. 
Por ello, me parece fundamental introducir un criterio genético, que se sobreimprime al cronológico propio de la historiografía, ya que nos ayuda a abordar la dimensión genealógica propia de la experiencia de "la experiencia histórica", nos permite anclar un origen en el marco de la infinitud del tiempo histórico y asimismo permite reubicar la erudición en los marcos de su propia natividad. ${ }^{30}$ Así, mientras una fuente primaria es indiscutiblemente una fuente primaria porque proviene de los usos contemporáneos al evento histórico que se consideran "primarios", en el caso de las llamadas fuentes secundarias estas podrían ser clasificadas ya sea a partir de su condición de erudición, ya sea en función de su condición nativa, que siempre aflora entre las palabras eruditas, a pesar de todo. ${ }^{31}$ De este modo el criterio ordenador ya no proviene de la presuposición de una diferencia inmanente entre sujeto y objeto de conocimiento, sino de los grados de mediación que cada uno de los discursos reviste con respecto al fenómeno construido como objeto de estudio. Así, mientras que se podría llamar "discursos de primer grado" a todos aquellos contemporáneos al fenómeno, los discursos de segundo orden son los que refieren a la historia vivida sin la inmediatez de la experiencia. ${ }^{32}$ Ahora bien, podríamos decir que los procesos de memoria también constituyen una experiencia. E incluso que lo es la construcción de conocimiento histórico sobre la historia. Por ello, así como en el caso de las fuentes primaras es posible diferenciar discursos eruditos y no eruditos, en el caso de los discursos de segundo orden cada uno de ellos debe ser abordado conforme a sus propias condiciones de producción y en función de las dinámicas y jerarquías que se establecen entre los unos y los otros. Así, estas fuentes de segundo grado podrían a su vez ser divididas en nativas y eruditas, lo que nos permitiría, entre otras cuestiones, establecer un ordenamiento (y un vínculo) entre la historia y la memoria.

\section{TEMPORALIDAD HISTÓRICA Y TRAUMA}

Se puede abordar este problema a partir de la consideración de dos niveles de indagación: uno general y uno específico. Pero parto del específico porque hace al general: en el caso del abordaje de procesos asociados fuertemente a conceptos que podríamos llamar, con Koselleck (2004), "conceptos fundamentales de la historia", ${ }^{33}$ como es el caso de violencia, que según dijimos constituye el vector de semantización en todos los órdenes discursivos que intervienen en la subjetivación del pasado reciente argentino, el problema es que se trata de conceptos que tienen entre otras la función de temporalizar la historia. Es decir que no sería posible presuponer la estructura del resultado de aquello que esos conceptos performan, por lo que no podríamos aplicar un concepto general para el estudio de un proceso particular.

Precisamente, por ello es tan importante la incorporación de otros órdenes de conocimiento que permitan a la historia trascender la historicidad de sus propias categorías "eruditas" que, hemos visto, son portadoras de su propio idiotismo o, lo que es lo mismo, de su propia historicidad. Así, he intentado superar esta tautología metodológica mediante el desdoblamiento en ambos casos (violencia y traumna) de su función indiciaria (y, por lo tanto, de su valor nativo) con respecto a su función propiamente conceptual o "erudita". Gracias a este desdoblamiento y a la consideración de la historicidad de sus usos, pude capitalizar los aportes de la filosofía de la historia benjaminiana retomada luego por Derrida, particularmente la idea de temporalidad diferida y de realización postergada (ver [1921] 1999 y 1994, respectivamente), para modelizar rudimentariamente una estructura de semantización del pasado reciente que se compone a partir de distintos vectores de semantización, con temporalidad cronológica y orientación temporal diversa, que nos permite concebir, entonces, lo traumático en la historia como el colapso entre dinámicas semánticas que tienden a la colisión aun cuando transcurren sobre ejes asintóticos: la violencia como estandarte del tiempo lineal y prospectivo propio de la cronología histórica, y el trauma como signo y seña de la cesura del tiempo histórico y de la introducción de la temporalidad retroactiva. Esta solución, aun cuando rudimentaria, tiene una relevancia capital, ya que me ha permitido componer el tiempo cronológico con la retroacción temporal propia del trauma (de Certeau, 1995). 


\section{IMAGINARIOS ESPACIALES}

En términos de espacialidad, si bien no es un aspecto que haya abordado específicamente todavía ni como objeto ni como problema teórico (lo que tengo como pendiente), considero oportuno señalar la importancia que reviste en cualquier proceso de semantización la cartografía imaginaria que sostiene la espacialidad de la historia. Porque, como hemos visto, a través de la dimensión imaginaria los sujetos son tocados por la palabra y constituidos en el plano de la acción. No existe mejor ejemplo que el de la clandestinidad para observar cuánto interviene la construcción social de los espacios físicos hasta el punto de tornar "invisibles" lugares y sucesos que ocurren a la luz del día. ${ }^{34}$ Asimismo, me atrae analizar la geografía imaginaria constituida por la argentinidad, esa experiencia tan particular de "pertenencia" expulsiva, amnésica de su propia historia, que nunca terminaré de padecer como persona crecida en el exilio. Por último, hay otra dimensión de la espacialidad que me interesa enormemente, que es la espacialidad imaginaria que sostiene y produce la disciplina histórica. Atenta siempre a los procesos subjetivos involucrados en el trabajo de los estudiantes que formo, ${ }^{35}$ he ido aprendiendo a poner en juego, como parte del trabajo de transmisión, la metarreflexión sobre los modos de constitución subjetiva e intersubjetiva de los sujetos históricos, y lo que se juega en ese plano de lo vincular que es invisible a los ojos pero que constituye el pilar de lo social como tal. Allí en el aula, en definitiva, en ese territorio también imaginario pero anclado en un aquí y un ahora único e insustituible, el conocimiento teórico-metodológico sobre mi "objeto de estudio" me permite también operar en la práctica misma, trascendiendo el ámbito de mi propia autotransformación.

\section{ACErca de las CATEgorías de Clase, género y RAZa}

En cuanto a los conceptos de clase, género y raza, cabe decir que, si bien no abordo específicamente esas dimensiones en sí ni como tema ni como categorías metodológicamente operativas, tiendo a trabajar con la idea de lector ideal, es decir, con una abstracción que se deriva en verdad de la propuesta institucional, política y cultural del medio de prensa abordado (ver Levín, 2013b). Personalmente, he quedado "atrapada" en Clarín por el trabajo de archivo acopiado, lo que llevaría a pensar más concretamente el problema, aunque ya escaparíamos del tema que nos convoca. Baste señalar que el análisis está absolutamente sujetado a la politicidad del medio de prensa en el cual se insertan los discursos (humorísticos o no humorísticos) que estudio.

Ahora bien, en otro nivel de análisis, la categoría de género me resulta significativa a nivel de la escritura de la historia y de las representaciones sobre "el" "historiador" que sostiene la escritura. Después de un buen tiempo de reflexión al respecto, he elegido mantener el uso del singular masculino no sólo por una cuestión estética de simpleza sino también porque me resulta un modo de tomar distancia y señalar que estoy hablando en términos generales y abstractos. Es decir que me funciona como un vehículo de desdoblamiento y mediatización (que desde luego suspendo cuando se trata de inscribir mi primera persona y allí sí de introducir todas las marcas de mis condiciones de género, raza, clase, e incluso mi inscripción genealógica dentro de la historia que estudio).

En cuanto al concepto de raza, creo que es el más difícil para la historia, ya que al mismo tiempo pre-supone un sujeto racional y de pleno derecho y una conciencia y una vocación por "dar voz a quien no la tiene". Parto entonces de la improductividad política y metodológica del recorte que el concepto impone para el tipo de indagaciones que efectúo. En este sentido, la no correspondencia entre el sujeto de la historia y el sujeto de la Historia $^{36}$ es universal y transversal a las diferencias de clase y género, aun cuando en su expresión histórica la clase y el género determinan en gran medida las condiciones de la fuerza y la violencia que gesta la historia. 


\section{ACERCA DE LOS CRITERIOS DE "RIGUROSIDAD” EN LA INVESTIGACIÓN HISTÓRICA}

Por todo lo anteriormente expuesto, considero que la rigurosidad tiene que ver con la coherencia y la correspondencia entre los fundamentos ontológicos que definen nuestro objeto de la disciplina (que a su vez enmarca y contiene los objetos de investigación propiamente dichos de un trabajo empírico) y el desarrollo de la metodología de investigación, algo que podríamos denominar coherencia epistemológica, que entiendo como la concordancia entre el nivel teórico y el empírico del quehacer del trabajo de historiar que, como hemos visto, requiere de la construcción de conceptos operativos capaces de lograr esa articulación. Dicho de otro modo, podríamos afirmar que hay rigurosidad si las categorías que utilizo en mi investigación me permiten construir un vaso comunicante entre el trabajo de archivo y mis presupuestos teóricos de modo tal que el resultado del trabajo empírico constituya realmente un aporte capaz de ser enunciado en el mismo registro discursivo en el que fueron formulados los objetivos de investigación.

Ahora bien, volviendo a los cauces de la perspectiva hermenéutica de la cual partimos, considero que la "rigurosidad" no es un valor en sí mismo, como tal vez sí podría serlo desde el punto de vista de un abordaje cientificista en el sentido clásico de la historia. ${ }^{37} \mathrm{Si}$ lo considero relevante es porque está al servicio de otro valor mucho más importante, que es la transformación. Por ello, a diferencia de las llamadas posturas reconstruccionistas dentro de la hermenéutica (Lythgoe, 2009), que se proponen restituir los sentidos "originarios" de un artefacto cultural como es el caso del documento histórico, ${ }^{38} \mathrm{mi}$ intención consiste en ubicar y reponer distancias semánticas o hiatos de sentido entre sistemas discursivos involucrados en los procesos de semantización del pasado, con el fin último de propiciar y facilitar un proceso de transformación subjetiva en la historia que se vive aquí y ahora. De este modo, la noción gadameriana de fusión de horizontes, que supone la familiarización de lo extraño, debe ser ajustada en el marco de las nuevas historiografías vinculadas con el tiempo presente, inmediato, vivido o reciente, que plantean el desafío de desnaturalizar los sentidos de las palabras mediante la introyección del sujeto de conocimiento como sujeto de la historia. De este modo, al modelo de la historia como disciplina dadora de verdad histórica le contraponemos el modelo de la historia como dadora de sentido, en el sentido de un sentido nuevo, que hay que descubrir aun cuando no se pueda nombrar, y que etimológicamente nos lleva al significado pático del término: a lo que se "siente" en los sentimientos. Lo mágico es que, si tal como lo venimos presuponiendo, las condiciones ontológicas del objeto determinan las posibilidades de su conocimiento (2016 y 2020), el conocimiento podría actuar performativamente, transformando las consecuencias que los fundamentos ontológicos de sus condiciones de posibilidad le imponen.

\section{REFERENCIAS}

Adelstein, Andreina, Berri, Marina y Levín, Florencia (2018). Lingüística e historia reciente de la Argentina: un análisis interdisciplinario sobre la categoría de "violencia". Calidoscopio, septiembre/diciembre 2018, 424-436.

Agamben, Giorgio (2010). Ninfas. Valencia: Pretextos.

Barthes, Roland (2013). El discurso de la historia. En El susurro del lenguaje. Más allá de la palabra y la escritura (pp. 101-209). Buenos Aires: Paidós.

Benjamin, Walter ([1921] 1999). Para una crítica de la violencia. En Ensayos escogidos (pp. 109-129). México DF: Ediciones Coyoacán.

Borsani, María Eugenia (2001). Importancia de la obra de H.-G. Gadamer para el quehacer del historiador. En E. Adamovsky (Ed.), Historia y sentido. Exploraciones en teoria historiográfica (pp. 117-134). Buenos Aires: El Cielo por Asalto.

de Certeau, Michel (1985). La operación historiográfica. En J. Le Goff y P., Hacer la Historia. I. Nuevos problemas (pp. 15-35).Barcelona: Laia. 
de Certeau, Michel (1995). Psicoanálisis e historia. En Historia y psicoanálisis (pp.77-95), Ciudad de México: Instituto Tecnológico de Estudios Superiores de Occidente-Universidad Iberoamericana.

de Certeau, Michel (2010). Escrituras e historia. En La escritura de la historia (pp.15-29). México D. F. : Universidad Iberoamericana.

Derrida, Jacques (1994). Nombre de pila de Walter Benjamin. En Fuerza de ley. El "fundamento mistico de la autoridad" (pp. 69-151). Madrid: Tecnos.

Didi Huberman, Georges (2011). Ante la imagen: ante el tiempo. En Ante el tiempo. Historia del arte y anacronismo de las imágenes (pp. 31-97). Buenos Aires: Adriana Hidalgo Editora.

Gadamer, Hans-George (2017). Verdad y método. Vol. I. Salamanca: Sígueme.

Gay, Eugenia (2017). El tiempo en la Historik. Ensayo de crítica historiográfica. En Anuario de la Escuela de historia virtual, 8(12), 1-20.

Gómez Ramos, Antonio (2016). Historia de los conceptos. Cuando el lenguaje se cruza con la historia. Introducción a Koselleck. En R. Koselleck, Historia/Historia (pp. 9-23). Madrid: Trotta.

Jameson, Fredric (1995). Imaginario y simbólico en Lacan. Buenos Aires: El Cielo por Asalto.

Koselleck, Reinhart (2004). Historia de los conceptos y conceptos de historia. Revista Ayer No 53, 27-45.

Koselleck, Reinhart (2016). historia/Historia. Madrid: Trotta.

Levín, Florencia (2005). Arqueología de la memoria. Algunas reflexiones a propósito de Los vecinos del horror. Los otros testigos. Entrepasados, XIV(28), 47-63.

Levín, Florencia (2013a). Historia reciente. La historia antes de la historia. En colección La Universidad interviene en los debates nacionales, publicado por la Universidad Nacional de General Sarmiento y el diario Página/12.

Levín, Florencia (2013b). Humor político en tiempos de represión. Clarin, 1973-1983. Buenos Aires: Siglo XXI.

Levín, Florencia (2015). Humor gráfico. Manual de uso para la historia. Los Polvorines: Universidad Nacional de General Sarmiento.

Levín, Florencia (2016). On the potential usefulness of recent history for the historical present. Ponencia presentada en $2^{\circ}$ Conference of the International Network for Theory of History: "The practical past: on the advantages \& disadvantages of history for life", Ouro Preto, Brasil.

Levín, Florencia (2020). Un grano de arena en el mar. Lo que puede aportar la historia a la elaboración de pasados traumáticos. En Historia da Historiografia. International Journal of Theory and History of Historiography, V. 13, No 33, maio-ago. p. 309-339.

Lythgoe, Esteban (2009). Hermenéutica e historia. En Brauer, La historia desde la teoría. Una guía de campo por el pensamiento filosófico del sentido de la historia y del conocimiento del pasado (pp. 289-302). Vol. 1. Buenos Aires: Prometeo. .

Masotta, Oscar (1976). Reflexiones presemiológicas sobre la historieta: el esquematismo. En E. Verón, et al., Lenguaje y comunicación social. Buenos Aires: Ediciones Nueva Visión.

Naishtat, Francisco (2009). Refocalización historiográfica y cambio de régimen de historicidad. La controversia de la representación del pasado y las catástrofes históricas contemporáneas. En: nudler, Oscar et al., Espacios controversiales. Hacia un modelo de cambio filosófico y cientifico. Buenos Aires: Niño Dávila. p. 51-84.

Ricouer, Paul, (1999). La lectura del tiempo pasado: memoria y olvido. Madrid: Editorial Arrefice.

Sarlo, Beatriz (2005). Tiempo pasado. Cultura de la memoria y giro subjetivo. Una discusión. Buenos Aires: Siglo XXI.

Steimberg, Oscar (2001). Sobre algunos temas y problemas del ana\#lisis del humor gra\#fico. En Signo y Seña. Instituto de Lingüística de la Facultad de Filosoía y Letras, Universidad de Buenos Aires.

Verón, Eliseo (1996). La palabra adversativa. En E. Verón et al., El discurso politico. Lenguajes y acontecimientos (pp. 9-24). Buenos Aires: Hachette. 


\section{Notas}

1 El autor define el idiotismo como la marca de la particularidad del lugar desde donde habla el historiador y de la peculiaridad de su ámbito de investigación (1985, p. 67).

2 Lytgoe (2019) resalta el pasaje que se produce de la hermenéutica epistemológica a la hermenéutica filosófica a partir de la reelaboración heideggeriana del concepto de comprensión, en su carácter proyectivo y activo, como fenómeno fundamental del ser humano.

3 Con estas bellas palabras abre Gómez Ramos su estudio sobre historia/Historia de Koselleck. Ver [Colocar el nombre del autor] 2016.

4 Es cierto que las imágenes y otras formas de objetualización del tiempo también tienen esta capacidad de transportar huellas del pasado a través del tiempo (Agamben, 2010; Didi Huberman, 2011). Pero lo peculiar en el caso de la palabra es que la disciplina histórica se constituye a través del mismo dispositivo significativo que el de sus fuentes primarias (o al menos, sus fuentes preferenciales). Sobre el tema de la separación no pueden obviarse los aportes de Michael de Certeau (1985 y 2010).

5 En verdad es más complejo, como trataré de desarrollar más adelante, pero habría que decir que en verdad se trata de la historicidad de cada uno de los elementos que intervienen en la construcción de esas experiencias, pasada y presente, en cuanto tales.

6 Para una introducción a las nociones de conciencia histórica efectual y función de horizonte en Gadamer, ver Borsani, 2001.

7 Concuerdo con el señalamiento de Gay (2017, p. 3), quien ha establecido la existencia de una contradicción entre el proyecto de historización del lenguaje requerido por la hermenéutica filosófica y la pretensión de cientificidad de raíz kantiana propia de la escuela koselleckiana.

8 Que, desde esta perspectiva, se diferencian de las palabras por su polisemia y densidad semántica, a lo que se agrega el valor semántico que reviste la historicidad del concepto mismo.

9 Otra diferencia sustancial radica, como espero exponer más adelante, en distintas consideraciones teórico-metodológicas acerca de la temporalidad histórica. Así, mientras Koselleck tiende a considerar las transformaciones semánticas en un sentido evolutivo y proyectivo, yo hago un esfuerzo por considerar distintos vectores, ejes y temporalidades de semantización para dar cuenta metodológicamente de lo traumático como fractura de sentido.

10 En el mismo sentido, vale la pena tomar cuenta el modo en que Jameson resuelve esta dicotomía al descomponerla en términos de imaginario, simbólico y real según los conceptos de Lacan.

11 Dada la polisemia del término y el lugar que ocupa en mi trabajo, uso en este lugar itálicas para señalar que se trata del uso corriente.

12 La posibilidad de conceptualizar mi objeto en términos de ausencia de la huella de la experiencia (2020, en prensa) hubiera sido impensable sin los aportes de todas estas disciplinas.

13 Esto quiere decir que los sentidos no subyacen en ningún significante específico, ni en ninguna articulación discursiva determinada, pues no tener contenido ni materialidad prestablecidos es lo que define el sentido en su relación con la palabra.

14 Trabajo que, como vimos, a su vez es posible en el marco de la transportación de elementos provenientes de la epistemología y la filosofía de la historia al interior del trabajo historiográfico. En este sentido, se resalta tanto la artificialidad de la separación disciplinaria entre estas ramas del conocimiento como la de la necesidad del establecimiento de una división del trabajo que permita capitalizar productivamente el cúmulo acopiado de experiencias y conocimiento profesional acumulado.

15 No está de más citar la relevancia del concepto de Husserl, retomado por Ricoeur (1999, p. 18), de personalidad de rango superior para referir a aquellas entidades colectivas derivadas que surgen tras un proceso secundario de objetivación de los intercambios intersubjetivos y que es preciso no confundir con ninguna inmanencia.

16 Ver al respecto las observaciones de Roland Barthes sobre los vínculos entre referente y significante en Barthes en "El discurso de la historia" (2013).

17 Vale señalar que es precisamente lo que queda por afuera del discurso de la historia, es decir, la facticidad de los objetos empíricos, lo que sostiene la veracidad y la legitimidad del discurso histórico. Y es específicamente ése el punto que articula los debates teóricos acerca de la posibilidad de conocimiento de pasados traumáticos. Ver Levín, 2020, en prensa.

$18 \mathrm{El}$ autor acuña el término esquematismo para referir al grupo de reglas sencillas que es preciso compartir para leer una tira cómica. Ese sencillismo se asocia con una característica propia del género, que consiste en que los signos exhiben en sí mismos la evidencia del "lado palpable" de lo que los constituye. En otros términos, dice Masotta, la historieta tematiza permanentemente sus propias condiciones materiales (Masotta, 1976, pp. 108, 221).

19 Ver un abordaje panorámico del lenguaje del comic en Levín, 2015; particularmente sobre las características y funciones del "globo de diálogo" o baloom, ver pp. 29-32. 
20 Ese señalamiento general podría ser un tema de abordaje en sí mismo. Así, por ejemplo, la conceptualización realizada por Oscar Steimberg de humor gráfico como discurso de segundo orden, constituido como registro y espacio de transformacio\#n y transposición de signos y marcas discursivas provenientes de la oralidad, la gestualidad, la escritura y/o de cualquier otro ge\#nero y soporte media\#tico (2001, p. 7), permite considerar de modo productivo y novedoso a la historia como un discurso de segundo orden y atender desde esta perspectiva al modo en que ella genera vínculos con los discursos subyacentes en las fuentes primarias. Algo similar podría decirse de la problematización de la figura de autor (tan importante para la comprensión de una viñeta, ya que enmarca si se trata de un chiste irónico o humorístico) ocasionada por la mediación que los personajes efectúan entre éste y la realidad a la que refieren (Levín, 2013, pp. 22-23) Se trata siempre de la literalización de dimensiones del dispositivo de mediación discursiva que habitualmente permanecen invisibilizados.

21 Como explica Jameson (1995), el sujeto mediado por el lenguaje está irremediablemente dividido porque ha sido excluido de la cadena simbólica. Es al mismo tiempo representado y excluido de la cadena simbólica, con lo que sólo puede acercarse de modo asintótico a lo real. Ver especialmente pp. 28 y 53.

22 En efecto, entre 1999 y 2001 aprobé Historia de la Psicología, Psicoanálisis freudiano II, Psicología y Epistemología Genética, Psicoanálisis escuela francesa y Psicología Social en la Facultad de Psicología de la Universidad de Buenos Aires.

23 En relación con mi propio derrotero académico, es oportuno mencionar que el presente artículo constituye de algún modo el anverso de otro de índole más teórico-político (2020, en prensa).

24 Aunque es importante advertir que también forma parte de las categorías de las fuentes. Sobre esto, ver Levín 2020, en prensa.

25 Ver sobre este punto 2020, donde me aboco a la conceptualización del trauma como resto de la historia y a explorar las consecuencias epistemológicas de dicho enunciado.

26 Entiendo "vector semántico" o "vector de semantización" al/los término/s que nuclea/n la construcción de sentidos de una experiencia histórica a lo largo del tiempo.

27 Ver específicamente sobre este punto el trabajo empírico realizado en colaboración con colegas provenientes de la lingüística en Adelstein, Berri y Levín, 2018.

28 Estos lineamientos parten del presupuesto de que lo que podríamos llamar "lengua nativa" del historiador, que en términos históricos asociamos con la lengua materna y con los procesos de simbolización que se producen en el marco de la socialización temprana, se expresan de modo relativamente automático o no "controlado" en el lenguaje erudito de la historia.

29 La misma noción de fuente primaria conlleva un implícito que tiende a empobrecer los abordajes sobre el pasado. Esto es, que en tanto fuente "primaria", un documento es capaz de dar cuenta de una experiencia pasada. Como vimos más arriba, el primero de todos los hiatos que se encadenan en un proceso de construcción de sentido es el que enmudece al sujeto de la experiencia en el mismo momento en que toma la palabra.

$30 \mathrm{He}$ incorporado en Levín, 2016, la noción de “evento primigenio" como categoría operativa capaz de ordenar la perspectiva genealógica que incorporo.

31 En estos términos, se trataría de convertir el idiotismo en objeto de estudio.

32 Nuevamente, es preciso advertir que por "inmediatez de la experiencia” no entendemos su acceso inmediato, pleno ni mimético. Es interesante advertir los tempranos reparos que formuló Beatriz Sarlo (2005) a la fantasía de la historización de la experiencia (propia y) ajena.

33 El autor define los conceptos fundamentales de la historia como aquellas palabras sin las cuales la experiencia histórica no puede ser mencionada. Ver [Agregar el apellido del autor] 2002.

34 Algo de todo esto estaba claramente en latencia en el estudio que realicé a partir de los testimonios de vecinos que convivieron con lo que después identificaron como "horror", cuando todavía ni había definido mi objeto de estudio para la tesis doctoral. Ver Levín, 2005.

35 Hace más de 10 años que dicto un seminario de grado de investigación en historia en la carrera de Historia [de la Universidad Nacional de General Sarmiento.

36 Tomo las nociones de historia/Historia de Koselleck (2016).

37 Introduzco esta distinción ya que, si bien disiento del modelo nomológico deductivo propio de las ciencias sociales, y más en general de la consideración de la historia como una ciencia social, ello no supone que desconozca el valor "científico" de la tarea que realizan los historiadores, el encuadre público institucional que orienta el sentido de su práctica y la honestidad como principio fundante de la rigurosidad. De acuerdo con Michael de Certeau (1985), es verdaderamente científica la historia que es capaz de dar cuenta de sus propias condiciones de producción.

38 Hemos visto la imposibilidad de trabajar a partir de la consideración de un sentido original. 